\section{$\underset{\substack{\text { hommes } \\ \text { \& migrations }}}{ }$}

\section{Hommes \& migrations}

Revue française de référence sur les dynamiques

migratoires

$1331 \mid 2020$

Femmes engagées

\title{
Arezki Idjerouidene, Monsieur Arezki. Un destin à tire d'aile
}

Paris, Paris-Méditerranée, 2018, 286 p., 21,90€.

\section{Mustapha Harzoune}

\section{(e) OpenEdition}

\section{Journals}

Édition électronique

URL : https://journals.openedition.org/hommesmigrations/12027

DOI : 10.4000/hommesmigrations. 12027

ISSN : 2262-3353

Éditeur

Musée national de l'histoire de l'immigration

Édition imprimée

Date de publication : 17 novembre 2020

Pagination : 232-233

ISBN : 978-2-919040-52-0

ISSN : 1142-852X

Référence électronique

Mustapha Harzoune, "Arezki Idjerouidene, Monsieur Arezki. Un destin à tire d'aile », Hommes \&

migrations [En ligne], 1331 | 2020, mis en ligne le 01 novembre 2020, consulté le 06 janvier 2023. URL: http://journals.openedition.org/hommesmigrations/12027; DOl : https://doi.org/10.4000/ hommesmigrations. 12027 


\section{Monsieur Arezki.} Un destin à tire d'aile

Arezki Idjerouidene, Paris, Paris-Méditerranée, 2018, 286 p., 21,90 €.

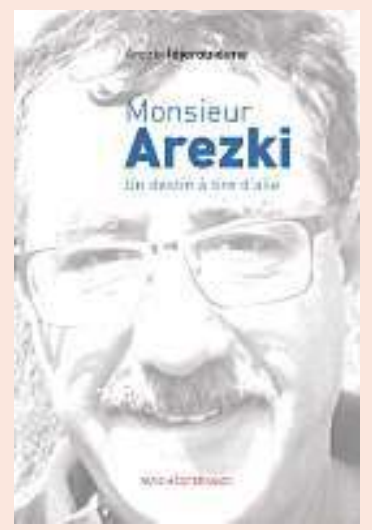

En voilà une trajectoire! Celle d'un gavroche du Djurdjura, ballotté dans les années 1950 entre guerre et misère coloniales qui deviendra le patron d'Aigle Azur, ci-devant deuxième compagnie d'aviation française. Arezki Idjerouidene a écrit cette autobiographie, quelques mois seulement avant d'être emporté par la maladie, à 61 ans, comme un legs à ses enfants et petits-enfants pour qu'« ils sachent un jour d'où ils viennent ». Il y raconte son parcours, ses engagements et valeurs. L'amour aussi qui, pendant près de 40 ans, le lia à Bettina, celle qui, au premier âge de l'exil, est devenue son épouse. Comme si l'amour et l'ailleurs s'étaient donnée la main pour accompagner cet homme humble, attentionné et entreprenant. Le récit est livré en deux temps : d'un côté, les 
souvenirs, de ceux qui font une vie, de l'autre, le quotidien d'un président d'un grand groupe, la part du «traceur de sillon » - tel est le sens du nom Idjerouidene.

Tout ramène aux premiers pas d'un gamin, orphelin de mère, devant souffrir une marâtre pour belle-mère. "Sesti », la grand-mère en kabyle, s'occupera de lui. Elle mourut âgée de 84 ans, « son décès reste le seul drame de ma vie, mon plus grand chagrin ».

De la guerre d'indépendance, il se souvient de la faim, des camps de regroupement, des atrocités de l'armée française. Elle laissera des traces chez l'adulte, comme ce début de panique qui pouvait le gagner devant une démonstration de vol d'hélicoptères: « Les hélicoptères, surtout, les hélicoptères, rapaces rageurs tournoyant au-dessus de nos têtes. " Ni pleurnicheries, ni ressentiment ici pour entraver la quête de liberté : " Ces souvenirs, je ne les ai pas enfouis au fond de ma cervelle, mais arrachés et abandonnés au bord du chemin, comme l'évadé scie la chaîne du boulet à sa cheville pour lui permettre d'avancer d'une démarche libre. »

Liberté aussi de croire ou de ne pas croire - le laïc regrette ce temps où « le respect des rituels religieux n'était pas l'objet d'une surveillance trop soupçonneuse ». Liberté de s'ouvrir au monde: " mon fils [...] il n'y aura que l'école qui pourra te sauver » prévient son père. "Oui l'école m'a sauvé témoigne l'auteur, et même bien plus que cela, elle m'a fait naître » et découvrir "l'ineffable plaisir d'apprendre, de comprendre, de m'ouvrir aux autres et au monde ».

Pourtant, à la rentrée 1963, « après plus d'un siècle d'humiliation et de servitude », le gamin éprouve une autre humiliation : interdiction de parler kabyle en classe ! Double et contradictoire émotion : d'un côté, l'ouverture (par l'école et l'indépendance), de l'autre, la fermeture (par une arabisation qui rejette une langue et sa population autochtones). Humiliations, punitions, répressions et même racisme seront autant de blessures «qui n'ont jamais vraiment cicatrisé ». "Alors je me révoltai » écrit-il, jusqu'à se forger une solide conscience politique, "conscience et fierté d'appartenir à une culture, à une langue, à un peuple».

L'autobiographie prend alors de forts accents politiques et pédagogiques (sur la situation culturelle en Algérie, la répression ou la montée de l'islam politique).

À 20 ans, il prend l'avion. Direction Paris! En secourant un vieil immigré algérien désemparé, il rencontre, à l'hôpital Lariboisière, Bettina, « qui va bouleverser radicalement le cours de ma vie ». Immigration et amour font bon ménage, n'en déplaisent aux grincheux, aux monomaniaques et aux flics qui débarquent à six heures du mat pour vérifier l'effectivité du mariage. « Ce viol de notre vie intime blessa Bettina plus profondément que moi. »

Pour Arezki Idjerouidene, l'exil n'est pas l'occasion de se répandre en larmes et en plaintes. Il eut aussi sa part de nostalgie et d'épreuves.

Mais « en voyant s'éloigner les côtes de mon pays natal, je n'avais pas le sentiment de m'exiler, et encore moins d'émigrer ». Non! "Telle une batterie, le corps et l'âme se rechargent à bloc d'énergie, d'espérances folles, de grands projets, de mirifiques ambitions. »

Un livre à l'image de son auteur, humble et sincère. Un viatique aussi, loin des passions tristes du moment. Une déclaration d'amour et de vie. De liberté.

M. H. 